
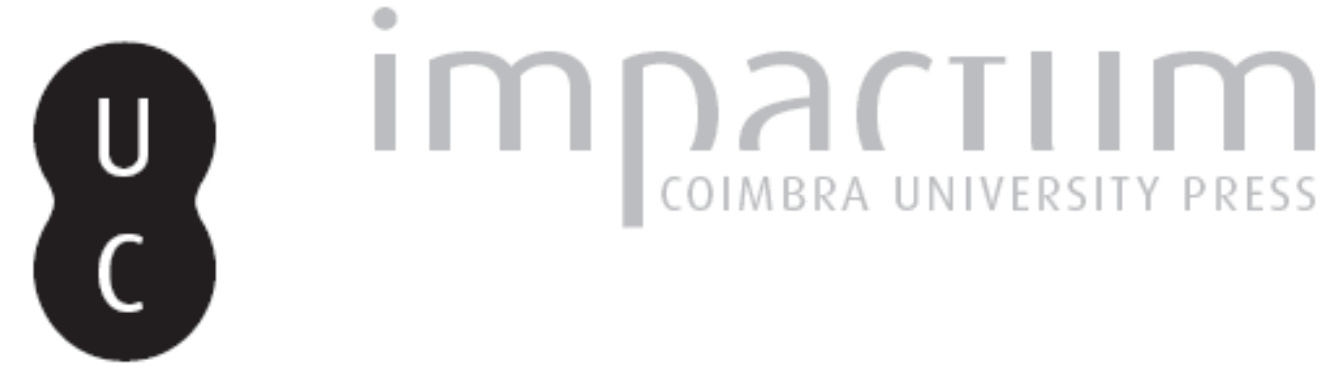

\title{
A obsessão do diagnóstico? Fronteiras da interpretação paleopatológica a propósito de um estudo de caso da Colecção de Esqueletos Idęntificados do Museu Bocage (Museu Nacional de História Natural, Lisboa)
}

Autor(es): $\quad$ Matos, Vítor

Publicado por: CIAS - Centro de Investigação em Antropologia e Saúde

URL

persistente:

URI:http://hdl.handle.net/10316.2/28864

DOI:

DOI:htpp://dx.doi.org/10.14195/2182-7982_25_6

Accessed : $\quad$ 26-Apr-2023 11:27:32

A navegação consulta e descarregamento dos títulos inseridos nas Bibliotecas Digitais UC Digitalis, UC Pombalina e UC Impactum, pressupõem a aceitação plena e sem reservas dos Termos e Condições de Uso destas Bibliotecas Digitais, disponíveis em https://digitalis.uc.pt/pt-pt/termos.

Conforme exposto nos referidos Termos e Condições de Uso, o descarregamento de títulos de acesso restrito requer uma licença válida de autorização devendo o utilizador aceder ao(s) documento(s) a partir de um endereço de IP da instituição detentora da supramencionada licença.

Ao utilizador é apenas permitido o descarregamento para uso pessoal, pelo que o emprego do(s) título(s) descarregado(s) para outro fim, designadamente comercial, carece de autorização do respetivo autor ou editor da obra.

Na medida em que todas as obras da UC Digitalis se encontram protegidas pelo Código do Direito de Autor e Direitos Conexos e demais legislação aplicável, toda a cópia, parcial ou total, deste documento, nos casos em que é legalmente admitida, deverá conter ou fazer-se acompanhar por este aviso.

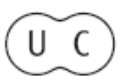




\title{
A obsessão do diagnóstico? \\ Fronteiras da interpretação paleopatológica \\ a propósito de um estudo de caso da Colecção de \\ Esqueletos Identificados do Museu Bocage \\ (Museu Nacional de História Natural, Lisboa)
}

\author{
Vítor Matos \\ Centro de Investigação em Antropologia e Saúde \\ Departamento de Antropologia \\ Universidade de Coimbra, Portugal \\ vmatos@antrop.uc.pt
}

Resumo Um dos desafios inerentes à interpretação paleopatológica radica na distinção entre o carácter normal e o patológico de determinadas alterações ósseas. Esta dicotomia nem sempre é linear e, frequentemente, dificulta ou impossibilita um diagnóstico retrospectivo concreto. O presente trabalho tem por objectivo exemplificar a fluidez da fronteira da interpretação paleopatológica, através do estudo de um esqueleto pertencente à Colecção de Esqueletos Identificados do Museu Bocage (Lisboa, Portugal). Este terá pertencido a uma mulher, doméstica, que em 1916, aos 35 anos, faleceu de tuberculose pulmonar. Das alterações macroscópicas observadas, destaca-se a presença de um canal no terço distal da clavícula esquerda com espessamento da metade acromial e bifurcação cortical do terço lateral balizada pela região do tubérculo conóide. $\mathrm{O}$ exame radiográfico confirmou a existência de uma zona de menor densidade na área descrita, não tendo revelado, no entanto, evidências de linha de fractura. Várias hipóteses etiológicas são discutidas assumindo-se como mais plausíveis: 1) fractura mal consolidada (intra-uterina, obstétrica ou ocorrida em tenra idade), cuja subsequente remodelação envolveu o encapsulamento das estruturas nervosas e venosas adjacentes, formando-se um canal circundado por tecido cartilagíneo; 2) bifurcação unilateral incompleta da clavícula. Neste estudo de caso, tal como em muitos outros, foi impossível efectuar um diagnóstico retrospectivo concreto. No entanto, e apesar das dificuldades e dos limites da interpretação paleopatológica, a análise de esqueletos humanos pretéritos é, com frequência, dominada por uma obsessão do diagnóstico, em detrimento, quer de descrições pormenorizadas, quer da exploração exaustiva das hipóteses etiológicas adscritas ao diagnóstico diferencial das alterações observadas.

Palavras-chave Paleopatologia; diagnóstico diferencial; diagnóstico retrospectivo; clavícula; fractura; autópsia. 


\begin{abstract}
The distinction between normal and pathological bony alterations during human skeletal remains analysis is one of the biggest challenges ascribed to the paleopathological practice. The frontiers of this dichotomy are often difficult to identify what restrict, or even precludes, the achievement of a specific retrospective diagnosis. The investigation herein depicted aims to exemplify the limits of the paleopathological interpretation. It is reported a case study from the Human Identified Skeleton Collection housed at the Museu Bocage (Lisboa, Portugal), namely that from a 35 years old woman who died, in 1916, from pulmonary tuberculosis. The main skeletal changes found, through macroscopical observation, were detected at the distal third of the left clavicle that presented acromial bulking, perforated by an abnormal canal, and cortical bifurcation confined to the region between the beginning of the clavicular lateral third and the conoid tubercle area. Although the radiographic analysis indicated low medullary density in the affected area no evidence of healing fracture callus was found. From the etiological entities considered for the differential diagnosis the most reliable ones are: 1 ) a poor consolidated fracture (intra-uterine, obstetric, or during early ages), which subsequent remodelling process incorporated the adjacent arterial and nervous structures resulting in the formation of a canal surround by cartilaginous tissue; 2) incomplete unilateral bifurcation of the clavicle. In the present case study, like in many others, it was impossible to accomplish a retrospective diagnosis for the etiology of the lesions described. Nevertheless, and despite the difficulties and limits of the paleopathological interpretation, the study of past human skeletons is often dominated by a diagnosis obsession instead of both detailed descriptions and exhaustive exploration and discussion of the differential diagnosis for the bony anomalies.
\end{abstract}

Key words Paleopathology; differential diagnosis; retrospective diagnosis; clavicle; fracture; autopsy.

\title{
Introdução
}

Um dos desafios inerentes à interpretação paleopatológica radica na distinção entre o carácter normal e o patológico de determinadas alterações ósseas. Esta dicotomia nem sempre é linear e, frequentemente, dificulta ou impossibilita um diagnóstico retrospectivo concreto (Aufderheide e Rodríguez-Martín, 1998; Ortner, 2003). A paleopatologia só excepcionalmente dispõe de critérios de diagnóstico autónomos e patognomónicos pelo que depende do conhecimento advindo, sobretudo, das ciências médicas (Grmek, 1983). Do espectro de enfermidades conhecidas na actualidade são escassas as que podem ser identificadas em remanescentes ósseos (Ortner 
e Putschar, 1981; Ortner, 1992; 2003; Roberts e Manchester, 2005). Não obstante, o estudo de esqueletos humanos pretéritos é, com frequência, dominado por uma obsessão do diagnóstico em detrimento, quer de descrições pormenorizadas das alterações observadas, quer da exploração exaustiva das respectivas hipóteses etiológicas.

No presente trabalho propõe-se exemplificar a fluidez que caracteriza as fronteiras da interpretação paleopatológica através de um estudo de caso, denunciando-se, ainda, a dificuldade, ou mesmo impossibilidade, de indagar a etiologia concreta de determinadas alterações ósseas.

\section{Material e métodos}

O estudo paleopatológico desenvolvido reporta-se à análise do esqueleto n. ${ }^{0}$ 706, observado no âmbito de uma investigação prévia (Matos, 2003; Matos e Santos, 2006). Trata-se de um indivíduo que integra a Colecção de Esqueletos Identificados do Museu Bocage - Museu Nacional de História Natural de Lisboa, Portugal. Atendendo à informação constante da respectiva ficha de registo, este esqueleto terá pertencido a uma mulher, natural de Lisboa, doméstica de profissão, falecida aos 35 anos de idade, em 1916, com tuberculose pulmonar.

Metodologicamente, a pesquisa baseou-se na observação macroscópica do esqueleto com o objectivo de rastrear eventuais alterações morfológicas e ou patológicas. A análise radiográfica efectuou-se na Clínica Universitária de Imagiologia dos Hospitais da Universidade de Coimbra, em equipamento com as seguintes especificações técnicas: mamógrafo General Electric, modelo Senographe DMR.

\section{Resultados e Discussão}

\section{Estado de preservação e modificações antrópicas}

O esqueleto encontrava-se bem preservado e bastante completo, tendose constatado a ausência de alguns ossos do carpo e do tarso, bem como das seguintes costelas: primeira e nona direitas e as décimas segundas. Por constrangimentos intrínsecos ao armazenamento da colecção osteológica não foi possível estudar o respectivo crânio. Não foram detectadas alterações tafonómicas assinaláveis. 
No âmbito das modificações de natureza antrópica assinalaram-se nove costelas com a extremidade esternal cortada. As superfícies afectadas onde ocorreu o corte, tanto no corpo das costelas, como nos respectivos fragmentos esternais que se preservaram, apresentavam uma secção irregular e áspera sem vestígios de remodelação óssea. Segundo Botella et al. (2000), este aspecto deriva de cortes, executados com instrumentos afilados, relativamente precisos e repetidos. O padrão resultante da secção das costelas difere bastante do decorrente de acidentes post mortem nos quais os bordos costais se apresentam bastante irregulares e com textura mais granulosa e de cor distinta, frequentemente mais clara do que a do restante osso.

Os cortes observados no âmbito do presente estudo terão sido executados segundo o plano sagital, o que coincide com o protocolo de autópsias elaborado por Neves, em 1930. Neste refere-se que o procedimento mais comum incluía a secção das cartilagens costais ou das costelas e que, neste último caso, o corte se executava com um costótomo, de baixo para cima (da décima à segunda costelas), ao longo da linha mamilar ou axilar (Figura 1). De facto, o esqueleto observado apresenta cortes contíguos, da sexta à terceira costelas esquerdas e da sexta à segunda direitas, tratando-se de uma padrão compatível com o resultante do exame autóptico descrito por Neves (1930). Desde modo, parece mais plausível que os cortes se tenham produzido durante uma autópsia do que serem consequências de fracturas ocorridas ante mortem.

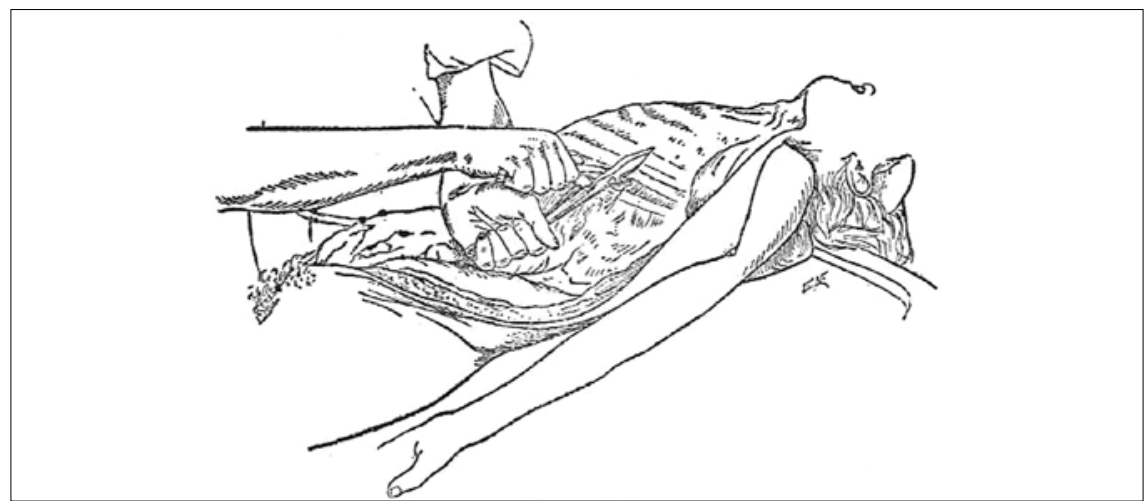

Figura 1. llustração do procedimento de corte das costelas com um costótomo durante uma autópsia (adaptado de Neves, 1930: 91). 
No passado recente desta prática médica, os ossos da cavidade torácica eram, e continuam a ser, frequentemente seccionados com vista à determinação do motivo do óbito (Sledzik e Micozzi, 1997). Recorde-se que para o indivíduo em estudo foi diagnosticada como causa de morte tuberculose pulmonar - enfermidade nem sempre fácil de distinguir de outras doenças respiratórias, devido à sobreposição de sinais e sintomas entre elas (Coutinho, 1957). Durante a primeira metade do século XX esta dificuldade era redobrada face à parca disponibilidade de meios complementares de diagnóstico (Carvalho, 1907; Coutinho, 1957). Neste contexto, não serão motivo de estranheza, portanto, as evidências autópticas encontradas nas costelas do esqueleto $n .^{\circ} 706$.

\section{Descrição das alterações na clavícula esquerda}

Da análise de todas as peças ósseas pós-cranianas, a alteração mais evidente detectou-se na clavícula esquerda, nomeadamente a presença de um canal, afunilado, com orientação horizontal e estendendo-se do bordo lateral posterior ao anterior, dividindo sagital e transversalmente o terço médio da região acromial do osso (Figura 2). A superfície superior da referida clavícula apresenta a zona de inserção do trapezóide bem demarcada por rugosidade óssea (Figura 2). Na face inferior destaca-se o exagerado desenvolvimento da linha trapezóide assumindo-se como uma pequena exostose projectada inferiormente.

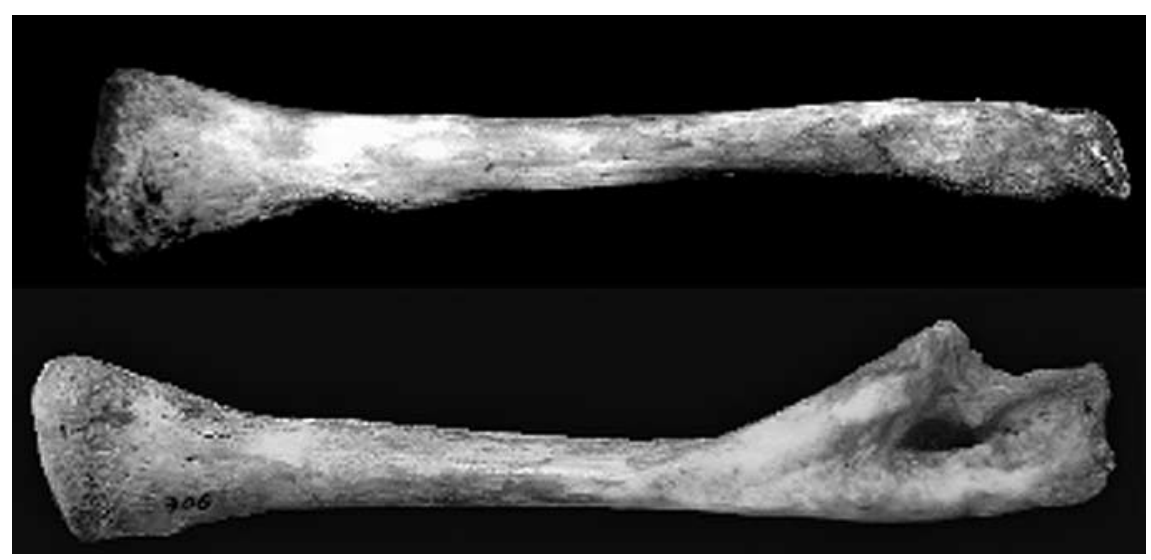

Figura 2. Clavículas direita (em cima) e esquerda (em baixo), ambas em norma posterior. 
Na região posterior (Figura 3) o referido canal apresenta uma abertura alta e larga ocupando todo o bordo lateral da clavícula correspondente, segundo Stone e Stone (1997: 105), à zona imediatamente abaixo da área de inserção do músculo trapezóide, e atravessando a mesma ao longo da linha trapezóide e afunilando até à parte posterior do orifício, no bordo lateral anterior do osso, abaixo da região onde, de acordo com Stone e Stone (1997: 111), se insere o músculo deltóide.

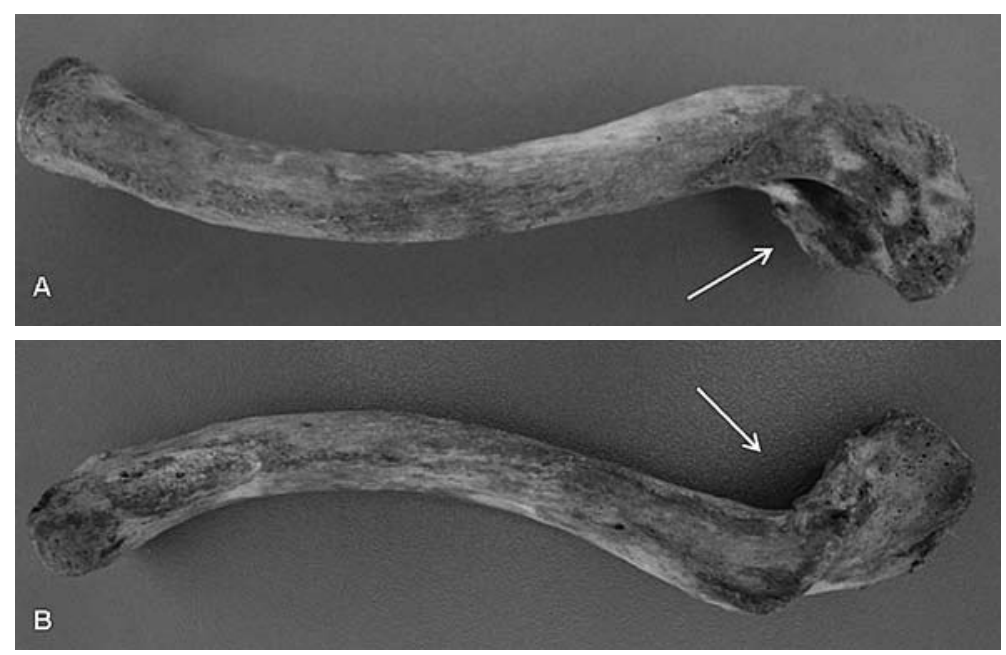

Figura 3. Clavícula esquerda. A. Em norma ântero-superior, com demarcação nítida da zona de inserção (seta) do músculo trapezóide. B. Em norma inferior.

Na porção anterior a clavícula apresenta espessamento no plano coronal e bifurcação ao longo do plano transverso da diáfise, com início no terço lateral e prolongando-se na direcção da zona acromial terminando abruptamente na tuberosidade conóide e na linha trapezóide (Figura 4). A região articular da extremidade acromial da clavícula volta a assumir um aspecto morfologicamente regular.

A análise radiográfica (Figura 5) revela um espessamento na metade acromial com bifurcação cortical do terço lateral do osso que se prolonga até ao tubérculo conóide e à linha trapezóide. Ao longo do plano coronal apresenta um orifício de contorno regular, ovalado, envolto por uma zona de tecido medular de menor densidade radiológica. Não se constataram linhas de fractura.

De salientar que não se observaram quaisquer modificações nem na clavícula simétrica (Figura 2) nem nas omoplatas. 


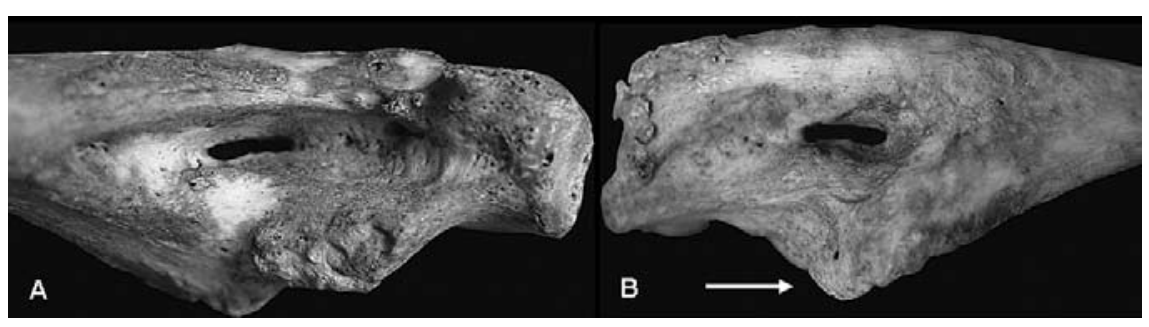

Figura 4. Pormenor do terço lateral da clavícula esquerda. A. Em norma anterior. B. Em norma posterior, sendo bem visível a projecção do tubérculo conóide (seta).

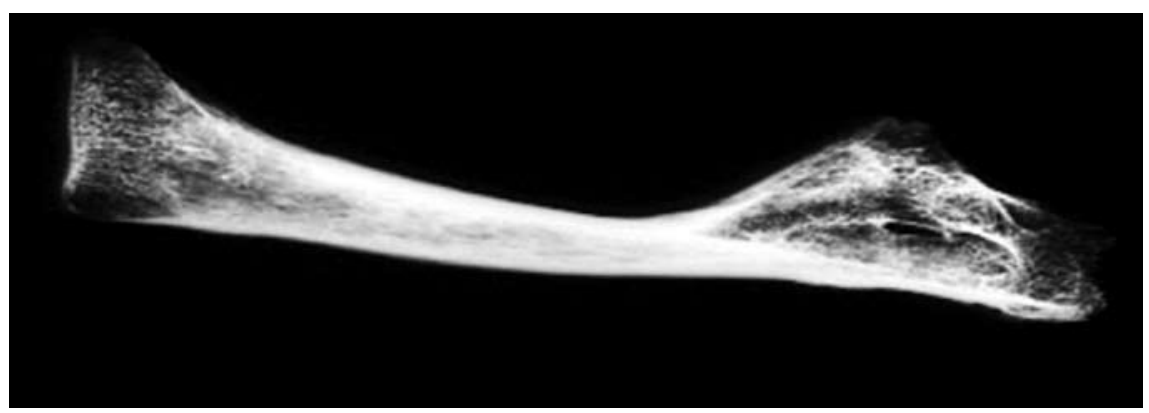

Figura 5. Radiografia da clavícula esquerda (norma anterior; voltagem: 28kV; exposição: 20mAs; DOI - distância objecto-imagem: 660mm).

\section{Outras alterações no esqueleto pós-craniano}

No segmento inferior da coluna vertebral, particularmente na quarta e quinta vértebras lombares e primeira sagrada, registou-se a presença de osteofitose moderada nas margens do corpo (Figura 6). Na junção discovertebral proliferam porosidades ou erosões. Estes indicadores sugerem a doença degenerativa do disco - discartrose - como possível etiologia (Rogers e Waldron, 1995). Detectou-se ainda a existência de um calo ósseo, em avançado estado de consolidação, na diáfise do $3 .^{\circ}$ metatársico esquerdo (Figura 7), possivelmente resultante de fractura. 


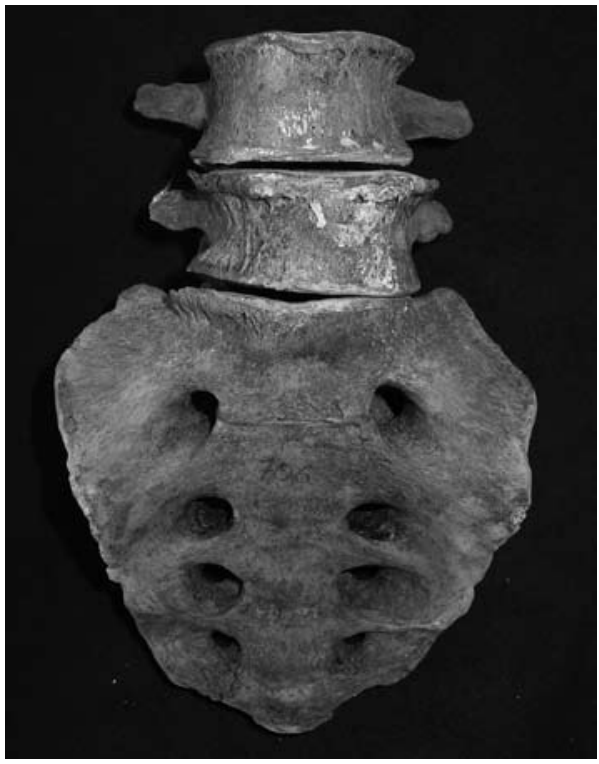

Figura 6. Segmento da coluna vertebral, em norma anterior, com osteofitose moderada nas margens do corpo das quarta e quinta vértebras lombares e na primeira sagrada, $\mathrm{e}$ porosidades na junção discovertebral

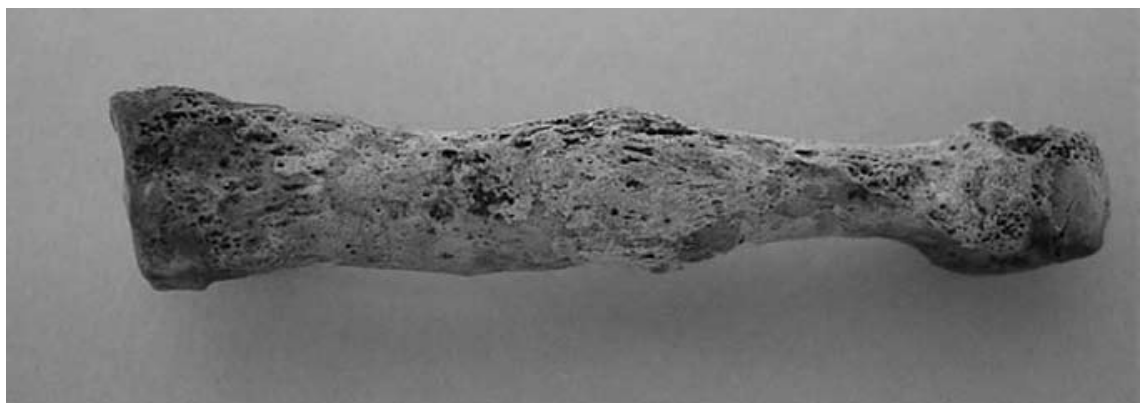

Figura 7. Calo ósseo na diáfise do $3 .^{\circ}$ metatársico esquerdo (norma dorsal).

\section{Discussão}

A alteração unilateral na clavícula esquerda, sem envolvimento das restantes estruturas da cintura escapular no esqueleto de uma mulher, catalogado com o número 706 da Colecção de Esqueletos Identificados do Museu Bocage, constitui uma singularidade paleopatológica. 
A tentativa de aduzir a etiologia da alteração descrita evoca a necessidade de se proceder a um diagnóstico diferencial baseado, sobretudo, em conhecimentos que advêm do estudo de variações anatómicas da clavícula e da consulta da literatura médica. No entanto, a revisão bibliográfica efectuada não revelou descrições similares.

As fracturas da clavícula são relativamente comuns (Resnick et al., 1996; Ortner, 2003), sendo uma das primeiras hipóteses a considerar no diagnóstico diferencial das modificações descritas. Contudo, de acordo com os dados clínicos actuais, a localização das alterações observadas no esqueleto $\mathrm{n}^{\circ}$ 706, nomeadamente no terço lateral da clavícula, não é a mais vulgar, correspondendo a apenas 15 a $20 \%$ das fracturas que afectam aquele osso (Resnick et al., 1996). Por oposição, Campillo (2001:320) refere que a extremidade lateral é uma das três regiões da clavícula mais sujeita a fracturas.

Após certos traumatismos, em particular os que provocam fracturas claviculares clinicamente designadas por "tipo II" (Resnick et al., 1996), o terço lateral da clavícula pode permanecer vários milímetros mais elevado que o acrómio devido à ruptura completa de ligamentos e à luxação daquele osso (Köhler, 1933). Nesta situação são afectados os tecidos adjacentes que se podem sobrepor aquando da remodelação, podendo ainda ocorrer uma união inadequada das porções ósseas fragmentadas, bem como osteomielite pós-traumática (Aufderheide e Rodríguez-Martín, 1998), sobretudo quando a fractura é aberta (Resnick et al., 1996). A alteração observada no caso descrito parece afastar a hipótese de infecção e/ou osteomielite já que, segundo Ortner (2003), quando tal se verifica a deformação é bastante mais acentuada.

A análise radiográfica efectuada descarta a possibilidade de se tratar de uma fractura recente já que não são visíveis traços indiciadores de descontinuidade óssea (Figura 5) e o exame macroscópico não revelou a existência de calo ósseo em fase de remodelação.

A possibilidade de se tratar de uma fractura antiga (intra-uterina, obstétrica ou de desenvolvimento) deverá ser considerada já que, durante o crescimento, dada a presença de tecido cartilagíneo calcificado, é maior o risco de traumatismo (Ortner, 2003). No entanto, as fracturas que ocorrem em tenra idade tendem a sofrer remodelação completa durante o desenvolvimento (Resnick et al., 1996; Ortner, 2003) não deixando vestígios na fase adulta. Nos casos de imobilização precária da fractura, ou na sua ausência, 
podem advir complicações tais como uma diminuição do tamanho do osso (Ortner, 2003) - o que não se observou na referida clavícula - e/ou a possível calcificação anormal dos ligamentos adjacentes com consequente encapsulamento dos vasos sanguíneos e nervos da região (Resnick et al., 1996), o que explicaria o espessamento e a formação de um canal, como o descrito.

Nalguns eventos traumáticos infligidos ao tecido muscular este responde através da produção de células diferenciadas, algumas delas percursoras do tecido esquelético, que concorrem para a formação de um hematoma e até, se necessário, de um calo ósseo (Johnson, 1964 in Ortner, 2003). No decurso do processo de dissolução do referido hematoma pode, em circunstâncias anómalas, formar-se osso no seio do tecido muscular. Esta condição é conhecida por myositis ossificans traumática (Aufderheide e Rodríguez-Martín, 1998; Ortner, 2003). O osso assim formado pode encontrar-se separado do esqueleto adjacente ou integrar-se nele. De acordo com Ortner (2003), um dos critérios de diagnóstico desta patologia é a presença de uma projecção óssea exuberante num local tendinoso ou ligamentar. No caso em discussão, e apesar da região afectada corresponder a zonas de inserção dos músculos trapezóide e deltóide, bem como à linha de inserção do ligamento para o músculo trapezóide, não se detectaram exostoses exuberantes compatíveis com um fenómeno de myositis ossificans traumática.

Ainda no âmbito do diagnóstico diferencial refira-se, como possível factor etiológico da alteração descrita, uma bifurcação incompleta da clavícula. Não se encontraram descrições de casos arqueológicos semelhantes, tratando-se de uma situação também rara na literatura clínica (Rutherfurd, 1921; Naitana, 1955; Sharma, 2003). Este fenómeno ocorre na fase embrionária aquando da duplicação do centro de ossificação (Ogata e Uhthoff, 1990), com posterior crescimento desigual dos segmentos duplicados e calcificação das estruturas cartilaginosas adjacentes de forma a permitir o funcionamento mecânico das estruturas musculares associadas, como constatou Sharma (2003). No entanto, este autor ressalva que a calcificação do ligamento coracoclavicular é bastante comum podendo, em exames radiográficos, ser interpretada erroneamente como uma duplicação da clavícula. No caso objecto de análise, a hipótese de ter ocorrido calcificação do ligamento coracoclavicular é mais remota já que o processo coracóide não apresenta qualquer alteração. 
Dada a localização e as características das alterações assinaladas foram consideradas pouco prováveis as seguintes hipóteses etiológicas:

1) Perfuração da clavícula por estruturas nervosas e/ou sanguíneas com a formação de um canalículo, situação comummente referida na literatura anatómica e antropológica (Santos,1927; Cunha e Morais, 1961; Saunders, 1978; Omokawa et al., 2005). Trata-se de um foramen localizado, por norma, na região medial da clavícula, atravessado pelo ramo médio do nervo supraclavicular (Prescher, 2000);

2) Pseudo-artrose congénita - alteração rara e localizada no terço médio da clavícula, com formação de pseudo-articulações que não se observaram no caso descrito (Hirata et al., 1995; Aufderheide e Rodríguez-Martín, 1998);

3) Defeito congénito idiopático, apesar de se tratar de um fenómeno raro na clavícula (Barnes, 1994; Resnick, 1996);

4) Tumor maligno que "no extremo acromial da clavícula se observa com bastante frequência, [...] caracterizando-se por rarefacção acentuada da substância esponjosa" (Köhler, 1933: 87), o que não se verificou na radiografia efectuada.

Como hipóteses inclusas no diagnóstico diferencial consideram-se, assim, como mais prováveis as seguintes: 1) fractura mal consolidada (intrauterina, obstétrica ou ocorrida em tenra idade) e cuja posterior remodelação envolveu o encapsulamento de estruturas nervosas e venosas adjacentes, com consequente formação de um canal circundado por tecido cartilagíneo; 2) bifurcação unilateral incompleta da clavícula.

\section{Conclusões}

A classificação de fenómenos patológicos em restos esqueléticos humanos é, na maioria dos casos, um "grande desafio" (Ortner, 1992: 6-7), como se constatou ao tentar indagar a natureza das alterações observadas na clavícula esquerda do esqueleto n. ${ }^{\circ} 706$ da Colecção de Esqueletos Identificados do Museu Bocage, e cuja etiologia concreta se revelou incognoscível.

Desta forma, a consciência dos limites da paleopatologia implica, necessariamente, que o corpo de entidades nosológicas inclusas no diagnóstico diferencial se anunciem de grande importância no estudo das manifestações 
ósseas de índole patológica, porque constituem, quase sempre, o limite do diagnóstico retrospectivo pretendido.

O estudo apresentado denuncia não só a fluidez que caracteriza a fronteira da interpretação paleopatológica como, também, a premência desta se alicerçar quer em descrições pormenorizadas quer na exploração exaustiva das várias hipóteses etiológicas sufragadas para o exercício do diagnóstico diferencial.

\section{Agradecimentos}

Ao Museu Bocage - Museu Nacional de História Natural, Lisboa; ao CIAS - Centro de Investigação em Antropologia e Saúde, Departamento de Antropologia, Universidade de Coimbra; à Clínica Universitária de Imagiologia dos Hospitais da Universidade de Coimbra; à Ana Luísa Santos, Carina Marques e aos revisores anónimos; à FCT - Fundação para a Ciência e Tecnologia (bolsa com a ref. SFRH/BD/16155/2004).

\section{Bibliografia}

Aufderheide, A.; Rodríguez-Martín, C. 1998. The Cambridge encyclopedia of human paleopathology. Cambridge, Cambridge University Press.

Barnes, E. 1994. Developmental defects of the axial skeleton. Niwot, CO, University Press of Colorado.

Botella, M.; Alemán, I.; Jiménez, S. 2000. Los huesos humanos: manipulación y alteraciones. Barcelona, Bellaterra.

Campillo, D. 2001. Introducción a la paleopatología. Barcelona, Bellaterra.

Carvalho, A. S. 1907. I - Quantos tuberculosos ha no paiz?; II - O erythema nodoso é uma tuberculide; III - Assumptos dignos de estudo para os futuros congressos. Comunicações apresentadas ao IV Congresso da Liga Nacional contra a Tuberculose. Lisboa, Centro Typographico Colonial.

Coutinho, A. C. [compil.] 1957. Dicionário enciclopédico de medicina. 2. ${ }^{a}$ edição. Lisboa, Argo editora. [Tradução e adaptação da 20. ${ }^{\text {a }}$ edição do Black's Medical Dictionary de Comrie, J. e Thomson, W.]

Cunha, A. X.; Morais, M. H. 1961. Estudo antropológico da clavícula dos portugueses. Contribuições para o Estudo da Antropologia Portuguesa, 7(5): $65-120$. 
Grmek, M. D. 1983. Les maladies à l'aube de la civilisation Occidentale: recherches sur la réalité pathologique dans le monde grec préhistorique, archaique et classique. Paris, Payot.

Hirata, S.; Miya, H.; Mizuno, K. 1995. Congenital pseudarthrosis of the clavicle: histologic examination for the etiology of the disease. Clinical Orthopaedics and Related Research, 315: 242-245.

Köhler, A. 1933. Röntgenología: los límites de la imagen normal y los comienzos de la imagen patológica. [Traducción de la $6^{\mathrm{a}}$ edición alemana por el Dr. Lorenzo Gironés]. Barcelona, Editorial Labor.

Matos, V. 2003. Incursões no trilho da tuberculose pulmonar: diagnóstico diferencial com base no estudo da Colecção de Esqueletos Identificados do Museu Bocage, Lisboa. Dissertação de Mestrado em Evolução Humana, Departamento de Antropologia, Universidade de Coimbra.

Matos, V.; Santos, A. L. 2006. On the trail of pulmonary tuberculosis based on rib lesions: results from the human identified skeletal collection from the Museu Bocage (Lisbon, Portugal). American Journal of Physical Anthropology, 130(2): 190-200.

Naitana, S. 1955. Fattori generali e fattori locali nel determinismo di una rara malformazione della clavicola: clavicola biforcata (con una radiografia fuori testo). Rassegna Medica Sarda, 57(9-10): 449-460.

Neves, A. 1930. Guia de autópsias. Volume 1. 2. edição. Lisboa, Imprensa Nacional de Lisboa.

Ogata, S.; Uhthoff, H. K. 1990. The early development and ossification of the human clavicle - an embryologic study. Acta Orthopaedica Scandinavica, 61(4): 330-334.

Omokawa, S.; Tanaka, Y.; Miyauchi, Y.; Komei, T.; Takakura, Y. 2005. Traction neuropathy of the supraclavicular nerve attributable to an osseous tunnel of the clavicle. Clinical Orthopaedics and Related Research, 431: 238-240.

Ortner, D. 1992. Skeletal paleopathology: probabilities, possibilities, and impossibilities. In: Verano, J.; Ubelaker, D. (eds.). Skeletal paleopathology: probabilities, possibilities, and impossibilities. Washington D.C., Smithsonian Institution Press: 5-13.

Ortner, D. 2003. Identification of pathological conditions in human skeletal remains. 2nd edition. New York, Academic Press.

Ortner, D.; Putschar, W. 1981. Identification of pathological conditions in human skeletal remains. (Smithsonian Contributions to Anthropology, 28). Washington D. C., Smithsonian Institution Press. 
Prescher, A. 2000. Anatomical basics, variations, and degenerative changes of the shoulder joint and shoulder girdle. European Journal of Radiology, 35(2): $88-102$.

Resnick, D. 1996. Congenital diseases: additional congenital or heritable anomalies and syndromes. In: Resnick, D. (ed.). Bone and joint imaging. 2nd edition. London, W. B. Saunders Company: 1167-1187.

Resnick, D.; Goergen, T.; Pathria, M. 1996. Traumatic, iatrogenic, and neurogenic diseases: physical injury. In: Resnick, D. (ed.). Bone and joint imaging. 2nd edition. London, W. B. Saunders Company: 717-818.

Roberts, C.; Manchester, K. 2005. The archaeology of disease. 3rd edition. London, Sutton Publishing.

Rogers, J.; Waldron, T. 1995. A field guide to joint disease in Archaeology. Chichester, John Wiley \& Sons.

Rutherfurd, H. 1921. Bifurcate clavicle. Journal of Anatomy, 55(4): 286-287.

Santos, E. 1927. Le canalicule claviculaire. Folia Anatomica Universitatis Conimbrigensis, 2(13): 1-21.

Saunders, S. R. 1978. The development and distribution of discontinuous morphological variation of the human skeleton. Ottawa, National Museum of Canada, Archaeological Survey of Canada (Mercury Series, 81).

Sharma, B. G. 2003. Duplication of the clavicle with triplication of the coracoid process. Skeletal Radiology, 32(11): 661-664.

Sledzik, P.; Micozzi, M. 1997. Autopsied, embalmed, and preserved human remains: distinguishing features in forensic and historic contexts. In: Haglund, W.; Sorg, M. (eds.). Forensic taphonomy: the post-mortem fate of human remains. New York, CRC Press: 483-495.

Stone, R.; Stone, J. 1997. Atlas of skeletal muscles. 2nd edition. Dubuque, IA, WCB - Wm. C. Brown Publishers.

Artigo recebido a 2 de Junho de 2008 e aceite a 13 de Junho de 2008. 